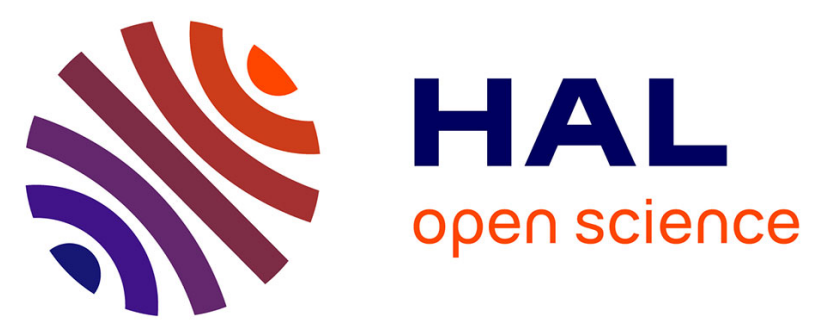

\title{
Plastic Strain Threshold Determination for White Layer Formation in Hard Turning of AISI 52100 Steel Using Micro-Grid Technique and Finite Element Simulations
}

\author{
Guang-Chao Nie, Ke Zhang, José Outeiro, Serafino Caruso, Domenico \\ Umbrello, Han Ding, Xiao-Ming Zhang
}

\section{To cite this version:}

Guang-Chao Nie, Ke Zhang, José Outeiro, Serafino Caruso, Domenico Umbrello, et al.. Plastic Strain Threshold Determination for White Layer Formation in Hard Turning of AISI 52100 Steel Using MicroGrid Technique and Finite Element Simulations. Journal of Manufacturing Science and Engineering, 2020, 142 (3), pp.034501-1 to 034501-7. 10.1115/1.4045798 . hal-02501123

\section{HAL Id: hal-02501123 \\ https://hal.science/hal-02501123}

Submitted on 6 Mar 2020

HAL is a multi-disciplinary open access archive for the deposit and dissemination of scientific research documents, whether they are published or not. The documents may come from teaching and research institutions in France or abroad, or from public or private research centers.
L'archive ouverte pluridisciplinaire HAL, est destinée au dépôt et à la diffusion de documents scientifiques de niveau recherche, publiés ou non, émanant des établissements d'enseignement et de recherche français ou étrangers, des laboratoires publics ou privés. 


\title{
Plastic strain threshold determination for white layer formation in hard turning of AISI 52100 steel using micro-grid technique and finite element simulations
}

\author{
Guang-Chao Nie ${ }^{\text {a }}$, Ke Zhang ${ }^{\text {a }}$, Jose Outeiro ${ }^{b}$, Serafino Caruso ${ }^{c}$, Domenico Umbrello ${ }^{c}$, \\ Han Ding a, Xiao-Ming Zhang ${ }^{\mathrm{a}, *}$ \\ ${ }^{a}$ State Key Laboratory of Digital Manufacturing Equipment and Technology, \\ Huazhong University of Science and Technology, Wuhan 430074, China \\ ${ }^{b}$ LaBoMaP Laboratory, Arts et Metiers ParisTech, 71250 Cluny, France \\ ${ }^{c}$ Department of Mechanical, Energy and Management Engineering, \\ University of Calabria, Rende, CS 87036, Italy
}

\begin{abstract}
White layer (WL) formation in metal cutting is generally found to have negative effects on the corrosion and fatigue life of machined components. Nowadays, the mechanism of the WL formation has not been understood very well, especially about the contribution of the thermal and mechanical loadings generated by the cutting process on WL formation. The relationship between subsurface plastic strain caused by mechanical loadings and the formation of WLs is of our concern. To address this issue, WL formation in hard turning of AISI 52100 under dry and cryogenic cooling conditions is investigated by subsurface plastic strain measurement using the microgrid technique, observed by scanning electron microscope (SEM). Due to the considerable low temperature, WL is mainly generated by mechanical effect rather than the thermal one, and this hypothesis is supported by physically-based finite element method (FEM) simulations. From the investigations, we discover the existing of plastic strain threshold, which governs the occurrence of WL in hard turning of AISI 52100 steel under cryogenic cooling conditions.
\end{abstract}

Keywords: Hard turning; White layer; Micro-grid; Plastic strain threshold; Cryogenic machining

\section{Introduction}

Hard turning is becoming increasingly accepted in industry as a potential substitute of grinding owing to its higher flexibility and economic efficiency. However, its application faces a great adverse issue, such as white layers (WLs) formation. The WL is characterized by higher hardness and brittle behavior when compared to the bulk material, having a negative impact on the corrosion and fatigue life of the machined components [1].

WLs formation is generally attributed to two mechanisms. The first mechanism is the dominant thermal-driven phase transformation, with a possible plastic strain activation. Stead [2] was the first one to report the concept of "white layer" and explain its formation by the thermal effects, which cause the austenitization of the machined surface, followed by martensite generation by rapid quenching. Chou and Evans [3] found that thermally driven

\footnotetext{
${ }^{*}$ Corresponding author, Email address: cheungxm@hust.edu.cn; zhangxm.duyi@gmail.com
} 
phase transformation are dominant in WLs formation. Umbrello and Rotella [4] reported that WLs are produced as the result of microstructural alteration, i.e., the generation of a martensitic structure in hard turning of AISI 52100 bearing steel. The second mechanism is the grain refinement by dynamic recrystallization (DRX) and/or severe plastic deformation (SPD). Ramesh et al. [5] reported that WLs formation at low-to-moderate cutting speeds was attributed to the grain refinement induced by SPD. Mondelin et al. [6, 7] reported that WLs were generated due to the DRX rather than by phase transformation, since the time isn't long enough to the austenitization occurs during finishing turning of AISI S15500 steel. A noticeable work was carried by Hosseini et al. [8], who characterized the microstructures of WLs induced by mechanical and thermal effects using transmission electron microscopy. They concluded that the microstructure of mechanically driven WLs was composed by broken-down and elongated sub-structure grains containing severely elongated secondary carbides, while the microstructure of thermally driven WLs contained equiaxed grains and broken-down sub-structure.

The relationship between WLs formation and residual stresses was also investigated in hard turning. Ramesh and Melkote [9] reported that WLs formation produces more compressive surface residual stress, which was attributed to volume expansion accompanied by phase transformation. However, Guo et al. [10] found the opposite in dry face hard turning of AISI 52100 bearing steel. They found tensile stress in the area of the WL, which becomes highly compressive in the deeper subsurface layers. They explained these results by the high temperatures accompanying WLs formation. Zhang et al. [11] presented the experimental results to show that using a smaller radial feed, the greater retained austenite content found in WLs was attributed to the generated compressive surface residual stresses, which possibly restricts the martensitic transformation.

The above-reported literature review shows that both high temperatures and SPD can be responsible for WLs formation, but which one is dominant in function of the applied cutting conditions (including the metal cutting fluid) remains unknown. To overcome this problem and identify the individual contributions of the mechanical and thermal effects on WL formation, as presented in other research papers [12-16], $\mathrm{LN}_{2}$ was used as a coolant to reduce the thermal effect to the utmost extent. Significant developments of cryogenic manufacturing processes during the last few decades were summarized by Jawahir et al. [17]. They showed the influence of various cooling strategies $\left(\mathrm{LN}_{2}, \mathrm{CO}_{2}\right)$ on the metal cutting performance (including forces, temperatures and tool wear) and machined surface integrity.

The objective of this work is twofold. First, to obtain the relationship between subsurface plastic strain caused by mechanical loadings and the thickness of WL. Second, to quantify the effect of plastic strain on WLs formation in hard turning of AISI 52100. The plastic strain during cutting process is studied through the micro-grid technique, observed by SEM. In addition, finite element simulations of the orthogonal cutting process were conducted using a physically based material constitutive model. These simulations permitted to explain the cause of grain-size and micro-hardness variations, and to identify the individual contributions of thermal and mechanical loadings.

\section{Experimental Procedures}

\subsection{Experimental Set-up and Cutting Parameters}

Fig. 1 shows the experimental setup used in hard turning tests of AISI 52100 bearing steel $(68.2 \pm 0.44$ HRC) under orthogonal cutting conditions on a lathe machine (left side of the figure), and the details about the cutting 
tool and micro-grids (right side of the figure). In order to promote the WLs formation, CBN inserts with a chamfer land of $0.10 \mathrm{~mm}$ and angle of $15 \mathrm{deg}$ were used (reference MGGN400-02) as shown in Fig. 1 (right side). These inserts are positioned in the tool holder (reference MGEHR2525-3C) to obtain the following tool geometry according to the ISO Standard 3002/1982: 0 deg cutting edge inclination angle, 0 deg normal rake angle and 7 deg normal clearance angle. These inserts also have a cutting edge radius of $20 \mu \mathrm{m}$ and a nose radius of $0.2 \mathrm{~mm}$.

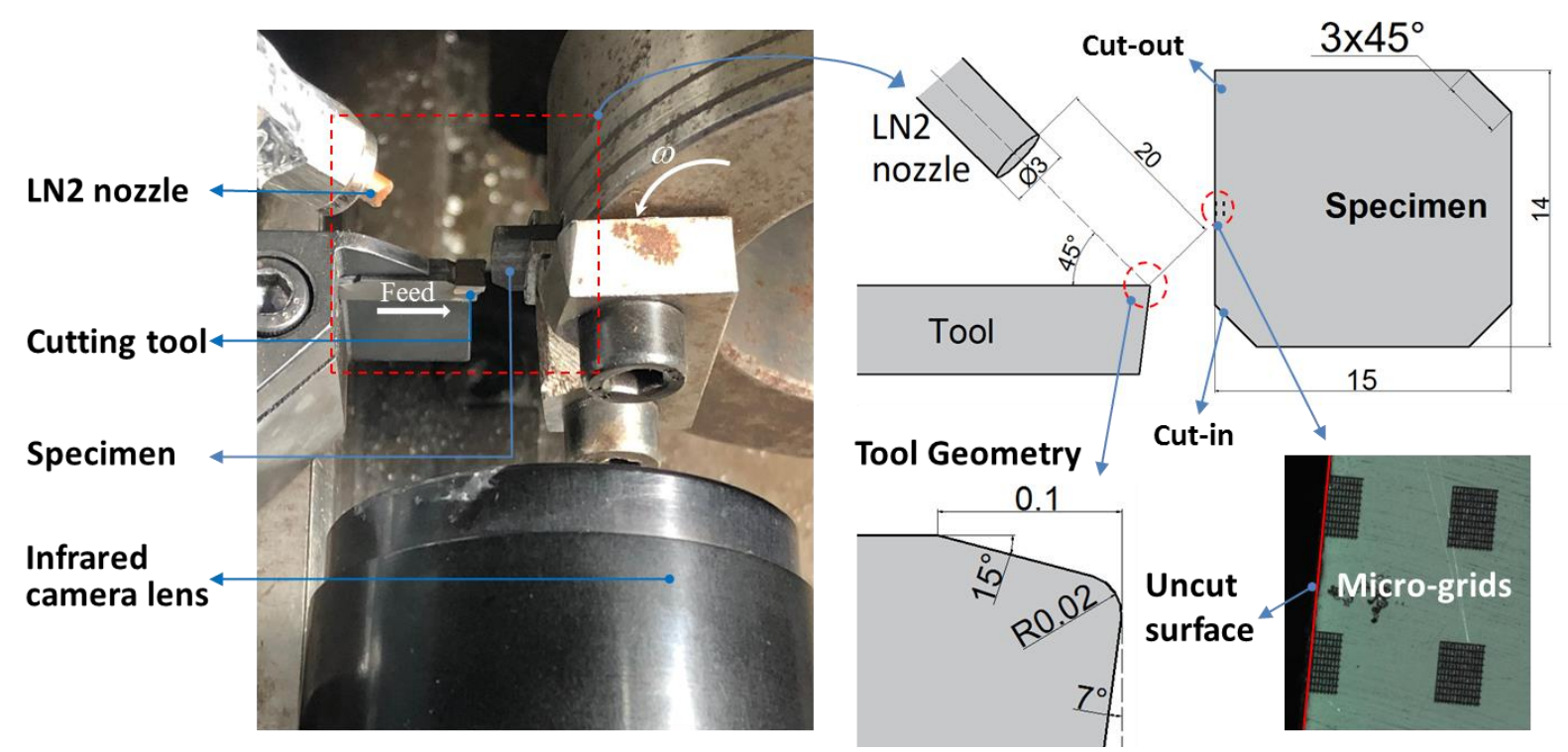

Figure 1. Experimental set-up for orthogonal cutting of AISI 52100 steel under both dry and cryogenic cooling conditions.

Orthogonal cutting tests are performed under dry and cryogenic cooling (using $\mathrm{LN}_{2}$ ) conditions. To deliver the $\mathrm{LN}_{2}$ to the cutting zone, a phase separator is used between the ranger and the tool holder. $\mathrm{LN}_{2}$ is projected into the tool rake face using a nozzle of $3 \mathrm{~mm}$ diameter, located at around $20 \mathrm{~mm}$ from the tool cutting edge and its axis is oriented at $45^{\circ}$ with the tool rake face (see Fig. 1). The velocity (v) of $\mathrm{LN}_{2}$ jet at the nozzle outlet can be calculated by:

$$
v=\sqrt{\frac{2 \cdot \Delta P}{\rho}}
$$

where $\Delta P$ is the difference between the pressure inside the phase separator and the atmospheric pressure; and $\rho$ is the density of $\mathrm{LN}_{2}$ at liquid phase, equal to $0.807 \mathrm{~g} / \mathrm{mL}$. The pressure $\Delta P$ is fixed at 4 bars to ensure a flow rate of $10 \mathrm{~L} / \mathrm{min}$. The cutting conditions used in the orthogonal cutting tests are given in Table 1 . Cutting speed, $V_{c}$, is kept constant and equal to $45 \mathrm{~m} / \mathrm{min}$, and the uncut chip thickness, $h$, varied from 0.03 to $0.1 \mathrm{~mm}$.

\subsection{Specimen Preparations and Measurements}

The material AISI 52100 bearing steel for cutting is under the heat treatment, i.e., spheroidizing annealing and then quenching as that in our previous work [11]. In order to minimize lateral (normal to the cutting direction) burr formation, and to obtain clear distorted micro-grids near the machined surface after cutting process, another polished specimen is needed, which is exactly the same as the workpiece except there is no mesh. Two specimens were clamped tightly to act as a single workpiece as shown in Fig. 2. In order to measure the WL thickness, optical micrographs were taken at three evenly spaced locations per sample. The WL thickness is measured at ten points 
for each micrograph and the average value was taken [11]. The most critical step of the pre-experiment is the micro-grids preparation using etching process. The technique of Focused Ion Beam (FIB) etching is used to inscribe the micro-grids with a $10 \mu \mathrm{m}$ pitch and a line width $3 \mu \mathrm{m}$ and a line depth $3 \mu \mathrm{m}$ on the polished specimen surface. The main parameters of FIB are voltage $20 \mathrm{KV}$, beam intensity $0.34 \mathrm{NA}$, and the one-time etching frame size is $200 \mu \mathrm{m} \times 100 \mu \mathrm{m}$. The etched micro-grids are shown in the right side of Fig. 1 .

Table 1 Cutting parameters and cooling conditions used in orthogonal cutting of AISI 52100 steel

\begin{tabular}{ccc}
\hline $\begin{array}{c}\text { Cutting speed, } V_{c} \\
(\mathrm{~m} / \mathrm{min})\end{array}$ & $\begin{array}{c}\text { Uncut chip } \\
\text { thickness, } \\
h(\mathrm{~mm})\end{array}$ & $\begin{array}{c}\text { Cooling } \\
\text { condition }\end{array}$ \\
\hline 45 & 0.03 & Dry \\
45 & 0.05 & Dry \\
45 & 0.08 & Dry \\
45 & 0.1 & Dry \\
45 & 0.03 & Cryogenic \\
45 & 0.05 & Cryogenic \\
45 & 0.08 & Cryogenic \\
45 & 0.1 & Cryogenic \\
\hline
\end{tabular}

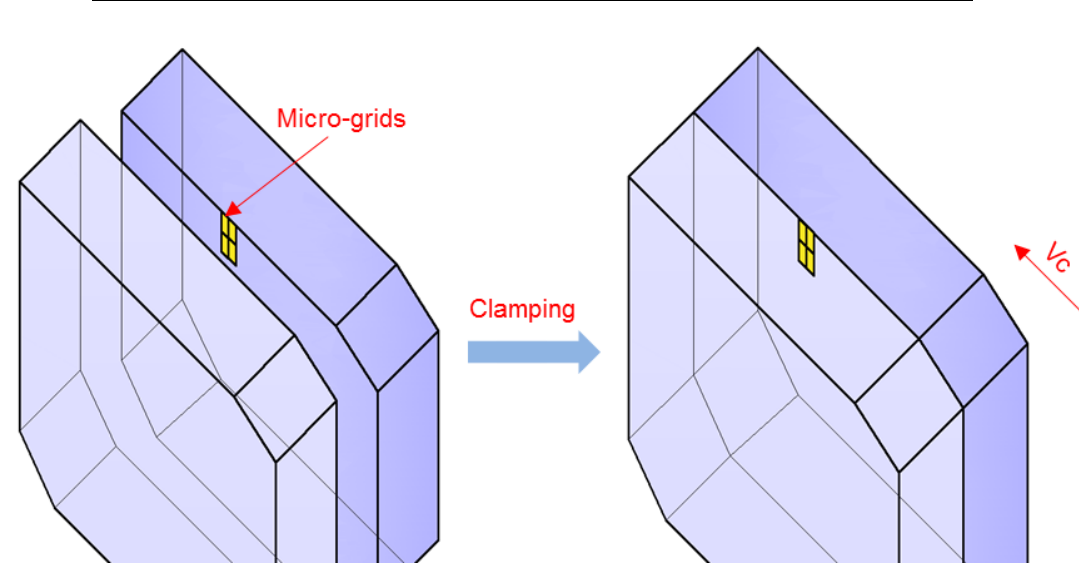

Figure 2. Details about the specimens preparation for the machining test.

In this study, for an accurate determination of the plastic strain at machined surface and subsurface, the images of the specimens with micro-grids are obtained after machining using SEM, rather than using CCD camera during machining. This method can be implemented in the case of $\mathrm{LN}_{2}$ spray cryogenic machining condition, under which the imaging technique $[18,19]$ for strain analysis is not applicable.

A piezoelectric dynamometric Kistler 9257B is used to measure the tangential and thrust cutting forces. An infrared camera is installed to measure the temperature distribution in the cutting zone (Fig.1). The emissivity of the AISI 52100 hardened-steel (68.2 HRC) is calibrated by adjusting the infrared camera emissivity, until the temperature of the workpieces measured by an infrared camera under the protection of oxide-free using nitrogen, and the pre-set heating temperature of electrothermal furnace are identical. The emissivity lies in the interval [0.33, $0.41]$ for a temperature range of $[200,600]^{\circ} \mathrm{C}$. Martensitic grain-size is obtained by measuring the long side of acicular martensite through SEM images. The work hardening generated by hard turning is quantified by measuring the subsurface micro-hardness. Indentations are performed by a Vickers indenter with a force of 0.05 kgf and a duration of 8 seconds using a Qness 10 A micro-hardness tester. The nearest distance of the indentation from the machined surface is around $10 \mu \mathrm{m}$. Besides, the minimum distance between two indentations is $20 \mu \mathrm{m}$. 


\section{Experimental Results}

\subsection{Forces, Temperatures and Microstructure}

As we know, the cutting forces serve as an important indicator of the effectiveness of the cutting models, and they have a significant influence on the generation of subsurface deformation. Fig. 3 shows the cutting forces signal when $h=0.1 \mathrm{~mm}$ : a slight cutting force $(\mathrm{Fc})$ increase is shown when comparing dry cutting condition with corresponding cryogenic one. Fig. 4 show the temperature distribution in the cutting zone for dry (Fig. 4a) and cryogenic (Fig. 4b) cooling conditions. This figure shows a reduction of the temperature in the cutting zone under cryogenic cooling conditions. In particular, the maximum temperatures in the chip and the machined surface under dry cutting are $495^{\circ} \mathrm{C}$ and $244^{\circ} \mathrm{C}$, respectively. While under cryogenic cooling condition, they are $323^{\circ} \mathrm{C}$ and 152 ${ }^{\circ} \mathrm{C}$, respectively. The temperature of the machined surface is not enough to promote austenization (austenite transformation temperature is $727^{\circ} \mathrm{C}$ ). Therefore, the white layer is not induced by thermal phenomena.

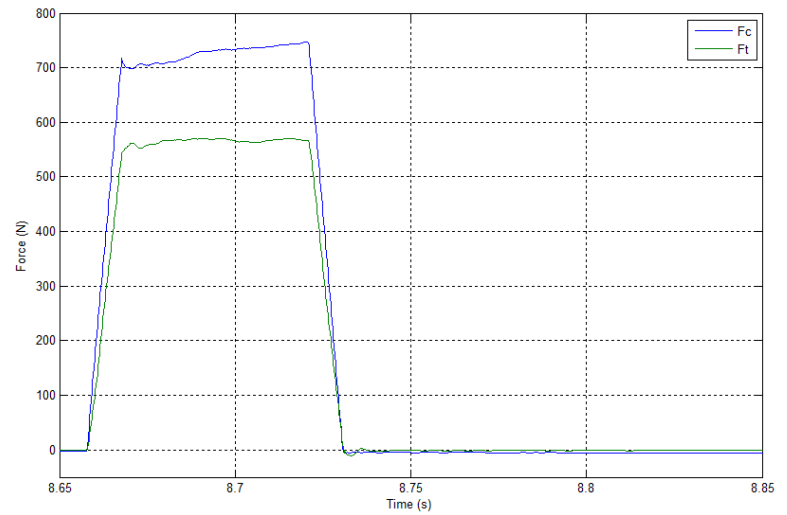

(a) Dry cutting

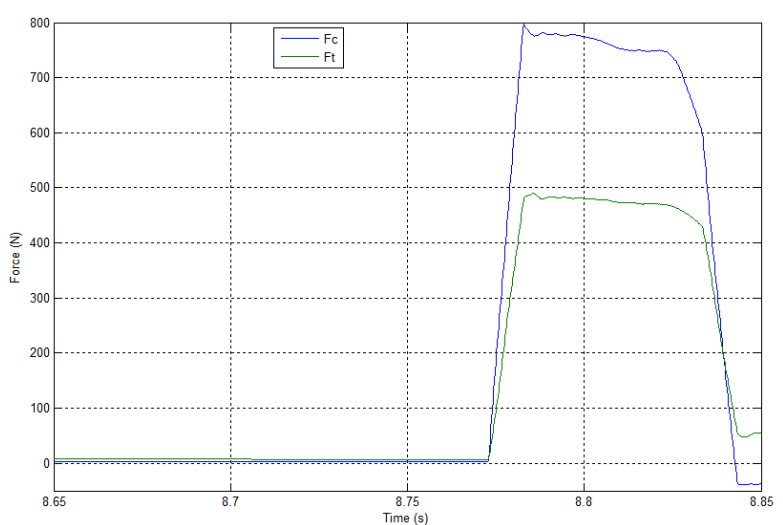

(b) Cryogenic cooling

Figure 3. Cutting forces signal (Fc: tangential cutting force and Ft: thrust cutting force) with $h=0.1 \mathrm{~mm}$ condition.

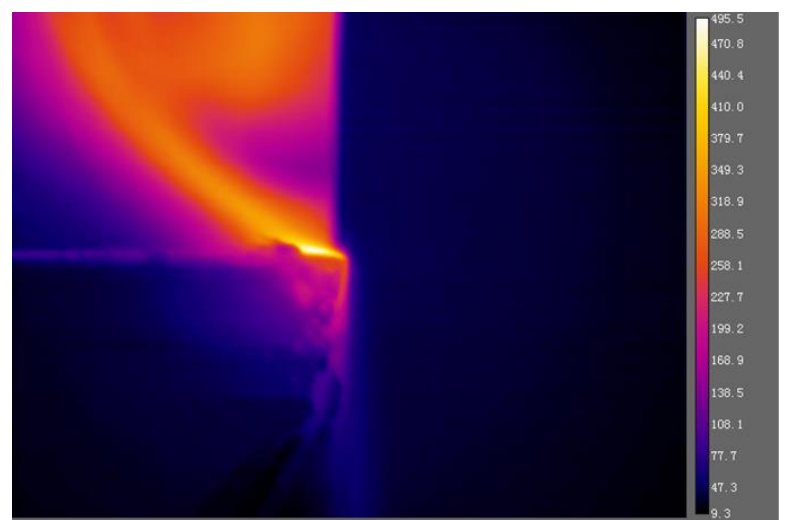

(a) Dry cutting

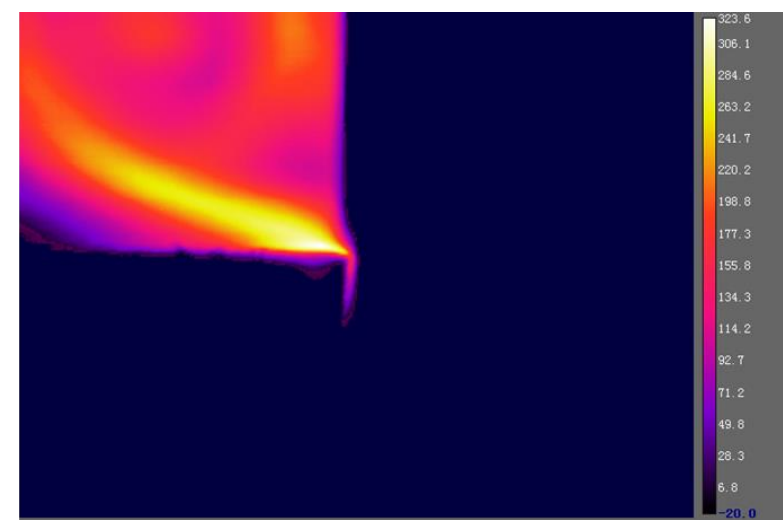

(b) Cryogenic cooling

Figure 4. Cutting temperature of tool-tip generated by machining with $h=0.1 \mathrm{~mm}$.

The hardness changes from 68.2 HRC (bulk hardness) to $69.3 \mathrm{HRC}$ ( $23 \mu \mathrm{m}$ beneath the machined surface) and to $70.8 \mathrm{HRC}$ (near the machined surface), under the cryogenic condition using $V_{c}=45 \mathrm{~m} / \mathrm{min}$ and $h=0.1 \mathrm{~mm}$. SEM images are used to analyze the surface and subsurface microstructure. The martensitic grain-size of $1.8 \mu \mathrm{m}$ near the machined surface and grain-size of $3.4 \mu \mathrm{m}$ at around $10 \mu \mathrm{m}$ beneath are observed (Fig. 5). The grain-size 
of the bulk material is $3.79 \mu \mathrm{m}$. The experimental results show a slightly increase of the material hardness and a decrease of grain-size from the bulk material to the machined surface.

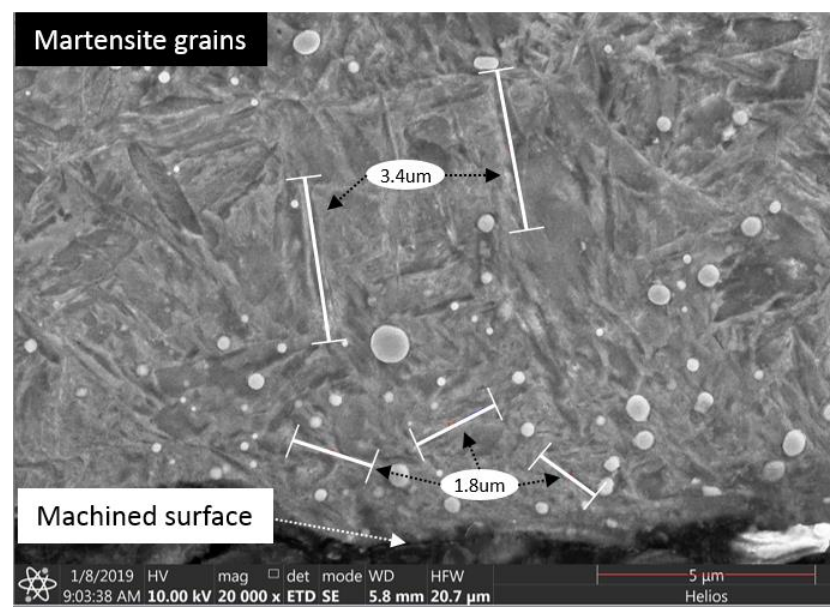

Figure 5. The grain-size of the subsurface.

\subsection{White Layer Thickness and Plastic Strain}

Fig. 6 shows the images of the deformed grids and WLs induced by orthogonal cutting under dry and cryogenic cooling. A WLs thickness of $1.82 \mu \mathrm{m}$ is registered when machining under dry cutting condition with an uncut chip thickness of $0.1 \mathrm{~mm}$, while a WLs of $1.55 \mu \mathrm{m}$ is registered with the same cutting parameters under cryogenic cooling. Fig. 6 also puts in evidence a plastic deformation from the machined surface until $15 \mu \mathrm{m}$ beneath it.

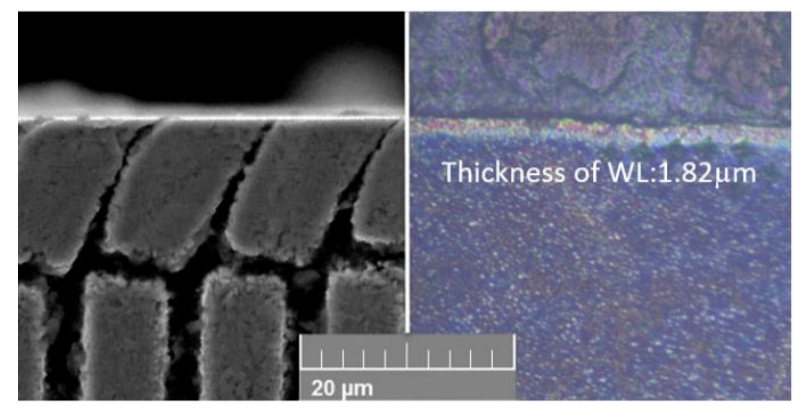

(a) Dry cutting

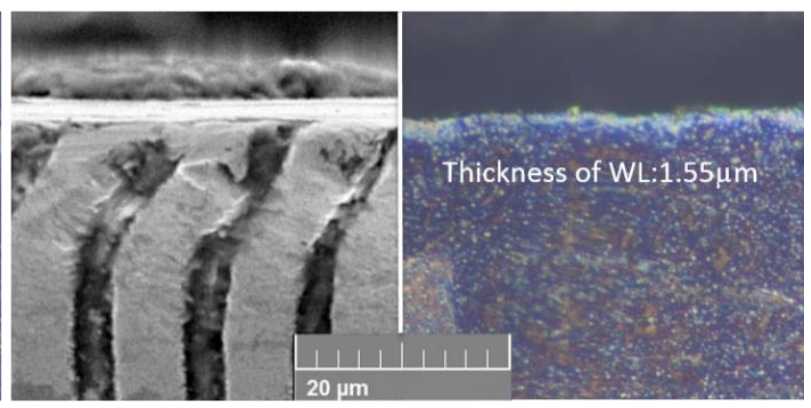

(b) Cryogenic cooling

Figure 6. Images of micro-grids on specimen and WL generated by machining with $h=0.1 \mathrm{~mm}$.

Fig. 7 shows the experimentally measured WLs thickness after machining. The WLs thickness under cryogenic conditions are $1.08 \pm 0.34 \mu \mathrm{m}$ for $\mathrm{h}=0.03 \mathrm{~mm}, 1.35 \pm 0.34 \mu \mathrm{m}$ for $\mathrm{h}=0.05 \mathrm{~mm}, 1.52 \pm 0.39 \mu \mathrm{m}$ for $\mathrm{h}=0.08 \mathrm{~mm}$, and $1.55 \pm 0.42 \mu \mathrm{m}$ for $\mathrm{h}=0.1 \mathrm{~mm}$. Fig. 8 (a) shows the plastic strain distribution beneath the machined surface after cryogenic machining at several uncut chip thicknesses. The measurements are performed on 10 specimens and the values of plastic strain are reported in Fig. 8 (b) by asterisks; and the average values are represented by the green circles, $0.61 \pm 0.07$ for $\mathrm{h}=0.03 \mathrm{~mm}, 0.64 \pm 0.07$ for $\mathrm{h}=0.05 \mathrm{~mm}, 0.68 \pm 0.12$ for $\mathrm{h}=0.08 \mathrm{~mm}$, and $0.66 \pm 0.1$ for $\mathrm{h}=0.1 \mathrm{~mm}$, respectively. A plastic strain threshold interval of $0.65 \pm 0.03$ was found for WLs formation under cryogenic machining. The plastic strain above this threshold induced by cryogenic machining leads to the formation of WLs, regardless of the applied uncut chip thickness. While considering the temperature is less than $200{ }^{\circ} \mathrm{C}$ at tool-tip in 
our measurements, this phenomenon is mainly attributed to mechanical loadings. Therefore, the SPD rather than the temperature dominates the WLs formation under cryogenic cooling.

The same analysis was performed under dry turning. Unfortunately, the plastic strain threshold to generate WLs cannot be identified for the different uncut chip thicknesses. This is due to that both SPD and thermal effects contribute to WLs formation, and the individual effects of plastic deformation cannot be distinguished.

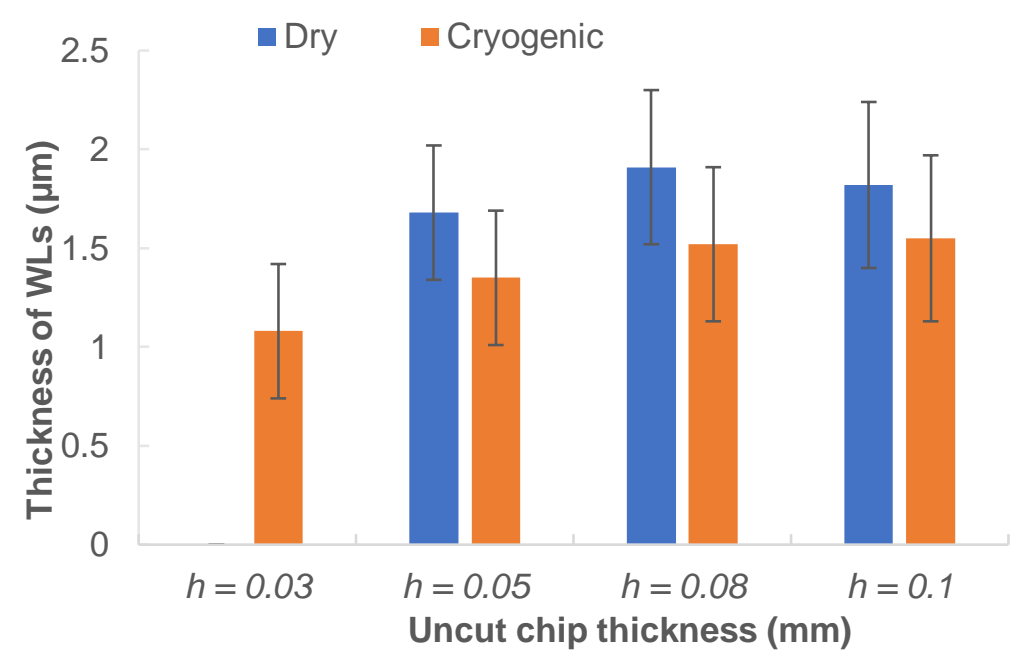

Figure 7. WLs thickness under dry and cryogenic cooling conditions.
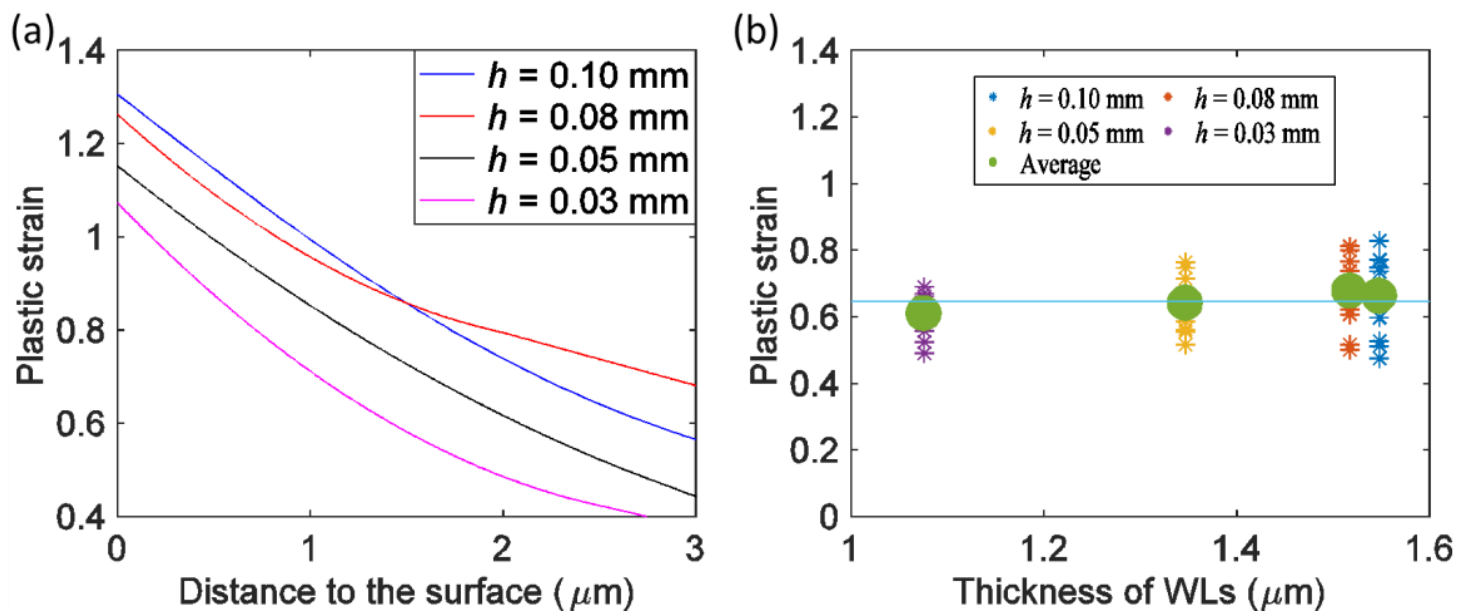

Figure 8. (a) Plastic strain in function of the depth beneath surface, and (b) plastic strain in function of the WL thickness, for several uncut chip thickness and under cryogenic cooling.

\section{Numerical Model}

In order to better understand the predominant mechanism of the WLs generation, the mechanical behavior of the AISI 51200 steel is represented by a modified version of the hardness-based material flow stress model proposed by Umbrello et al. [14]. The modification consists into the effect of grain refinement induced by dynamic recrystallisation (DRX) to the material flow stress. Therefore, coefficient $\mathrm{C}$ of the original flow stress model Umbrello et al. [14] was modified to include the grain refinement induced by DRX, and given by:

$$
C=a+\frac{k}{\sqrt{d}}(M P a)
$$


where $d$ is the average grain-size, $a$ and $k$ are two constants. By this modification, grain refinement (mainly mechanically induced) and phase transformation (mainly thermally induced) will modify the microstructure of the machined affected layer, influencing the material flow stress. Thus, the final thermo-mechanical material constitutive model of the AISI 52100 steel is represented by:

$$
\sigma=B(T) \times\left(\left(a+\frac{k}{\sqrt{d}}\right) \varepsilon^{n}+F+G \varepsilon\right) \times\left(1+\left(\log (\dot{\varepsilon})^{m}-A\right)\right)
$$

where the values of the constants $a, k, n, m, F, G$ and $A$ were adopted from Umbrello et al. [15], for the initial material hardness of 68.2 HRC. $\varepsilon$ and $\dot{\varepsilon}$ are the strain and strain rate, respectively.

The material constitutive model was used in an orthogonal cutting model, implemented in the commercial FEM software DEFORM-2D ${ }^{\mathrm{TM}}$, under plane-strain conditions and applying a coupled thermo-mechanical analysis. The updated Lagrangian formulation with remeshing technique is applied to simulate the chip formation. An isotropic hardening behavior was set for the workpiece assumed to deform plastically only, whereas the cutting tool was assumed as a rigid body. The workpiece was meshed with 18000 isoparametric quadrilateral elements; meanwhile, 3500 elements were set for meshing the cutting tool. Aiming to achieve an accurate prediction of the investigated variables, high mesh-density has been set and used for the workpiece around the cutting edge and along the machined surface, presenting an average edge size of $5 \mu \mathrm{m}$. The thermal boundary conditions for both dry and cryogenic cooling were set according to Umbrello et al. [14]. In particular, cryogenic cooling was simulated adding an region of cooling at $-196^{\circ} \mathrm{C}$, positioned in order to include the machined surface and the tool rake face, and using a convection coefficient, $h_{\text {cryogenic }}$, given by the following equation:

$$
h_{\text {cryogenic }}=-0.000008 \cdot T^{3}-0.0149 \cdot T^{2}+44.397 \cdot T+10162
$$

A shear friction model was also implemented with Brozzo's fracture criterion [15] to simulate serrated chip formation. Hall-Petch (H-P) equation and Zener-Hollomon (Z-H) parameter were implemented through user subroutine for hardness and grain refinement predictions, respectively. The two coefficients related to recrystallized grain-size and critical strain were calibrated, for an initial grain-size of $3.79 \mu \mathrm{m}$, using the calibration procedure reported by Umbrello et al. [14].

The developed FE model allows showing individually thermal and mechanical influence on microstructural changes. In fact, for each step the FE model compares the current strain with the critical strain $\varepsilon_{c}$, if the latter is lower than the current strain, DRX takes place leading to a modification of the microstructure of the machined affected layer (i.e. grain-size refinement and hardness modification). At the same time, the orthogonal cutting model determines if the predicted temperatures could initiate phase transformation leading to the hardness variation.

As overall results, the model determines if hardness variation is mainly due to thermal contribution induced through phase transformations, or due to mechanical contribution induced through SPD.

\section{Comparison between Experimental and Simulated Results}


Fig. 9 shows both measured and simulated forces for dry and cryogenic cooling conditions. A good agreement can be observed between simulated and experimental forces, with an error ranging between $-14 \%$ and $13 \%$, for cryogenic cooling, and between $-12 \%$ and $+12 \%$, for dry condition. As far as the tangential cutting force $\left(\mathrm{F}_{\mathrm{c}}\right)$ is concerned, both experimental and numerical results show a slight increase under cryogenic cooling due to the influence of low temperatures in material work hardening and grain refinements. No significant changes were observed for thrust cutting forces $(\mathrm{Ft})$ under the same conditions.

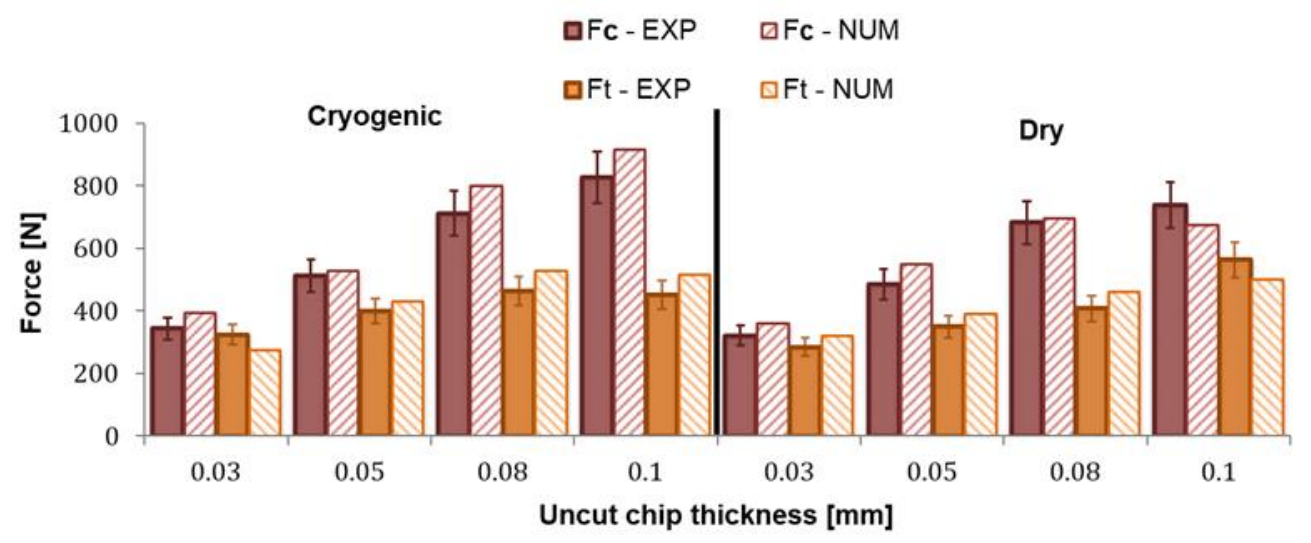

Figure 9. Comparison between measured and predicted tangential Fc, and thrust Ft, cutting forces during cryogenic and dry machining.

Fig. 10 shows both measured and simulated grain-size under dry and cryogenic cooling conditions for different uncut chip thicknesses. The grain-size is quite well predicted in the first microns beneath the machined surface. However, the difference between measured and simulated grain-size increases with the depth beneath the surface. Both methods show a grain refinement as the distance from the surface decreases. Moreover, a small decrease in grain-size is observed when the uncut chip thickness changes from 0.03 to $0.1 \mathrm{~mm}$.

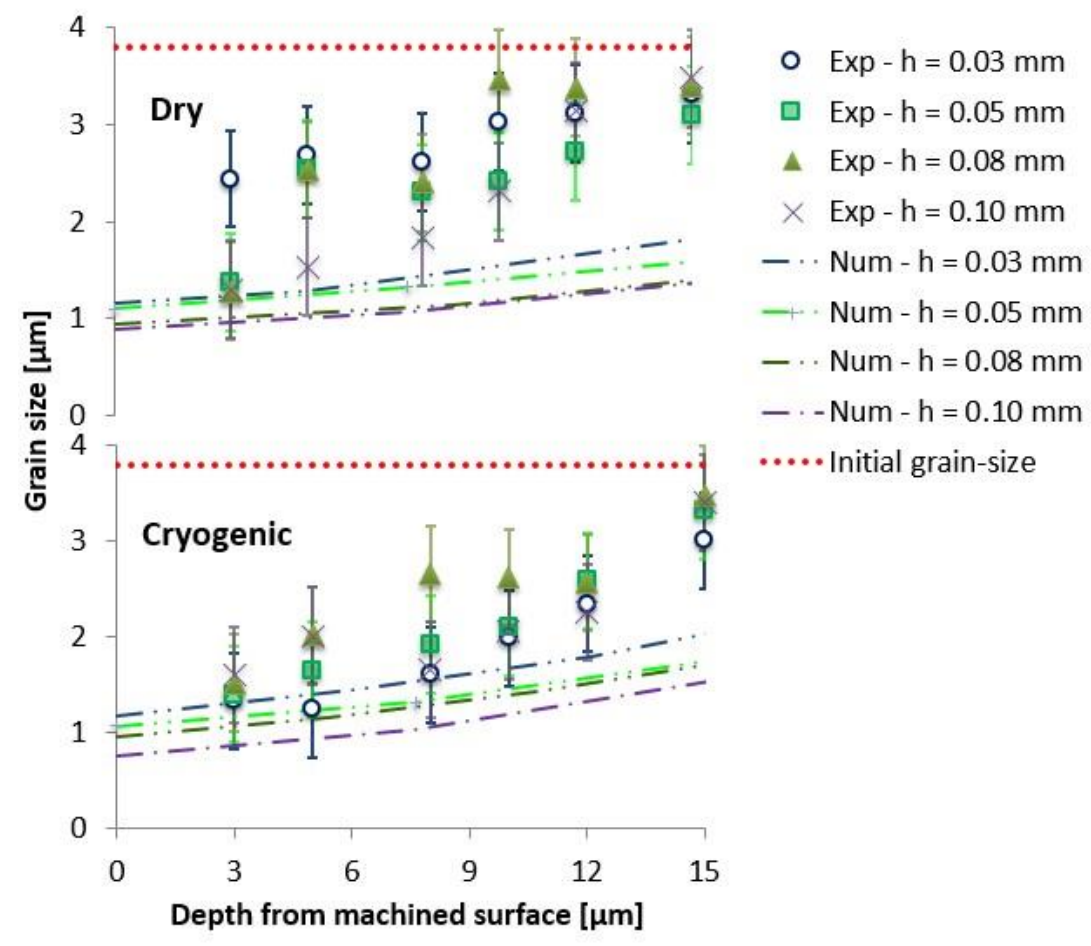

Figure 10. Comparison between measured and predicted grain-size for dry and cryogenic cooling. 
Fig. 11 shows a comparison between simulated and measured hardness for dry and cryogenic cooling. As also observed for the grain-size, the hardness is quite well predicted in the first microns beneath the machined surface, but the difference between measured and simulated hardness increases with the depth beneath the surface. Both methods show an increase in the hardness as the distance from the surface decreases. Moreover, a small increase of the micro-hardness with the uncut chip thickness is observed, which is related to the grain refinement.

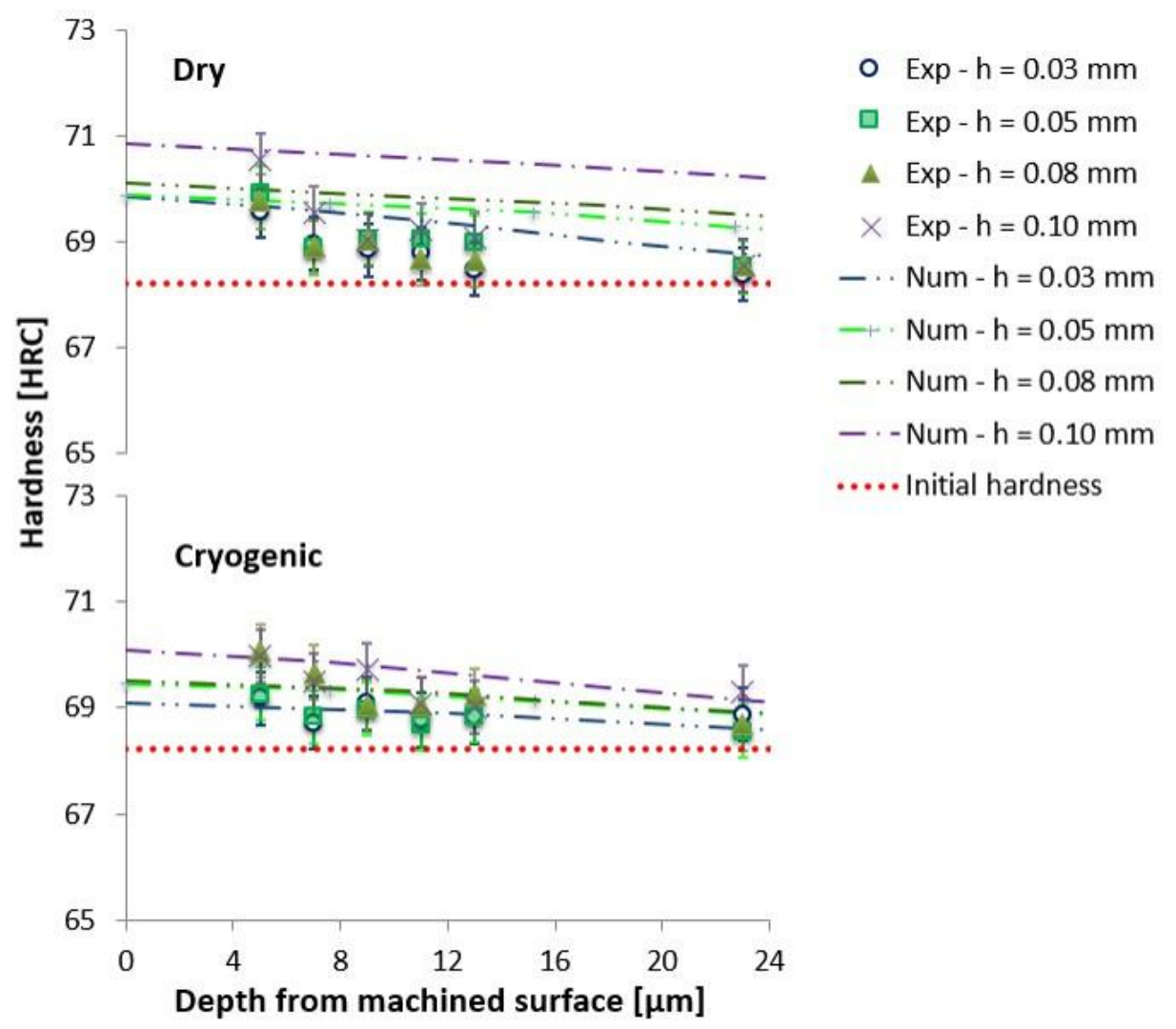

Figure11. Comparison between measured and predicted hardness for dry and cryogenic cooling.

Fig. 12a and 12c show respectively the distributions of the grain-size and hardness in the machined surface and subsurface, when the severest cutting condition is applied (corresponding to the highest uncut chip thickness). Fig. $12 \mathrm{~b}$ and $12 \mathrm{~d}$ show respectively the thermal (through phase transformations) and mechanical contributions to the material hardness of the machined affected layer. Analyzing these two figures, it can be concluded that the hardness distribution in the machined surface and subsurface is only due to the mechanical contribution. These simulation results confirm the experimental outcomes that grain-size and hardness distributions in the machined surface and subsurface are only mechanically induced (by SPD) when cryogenic cooling is applied. 
(a)

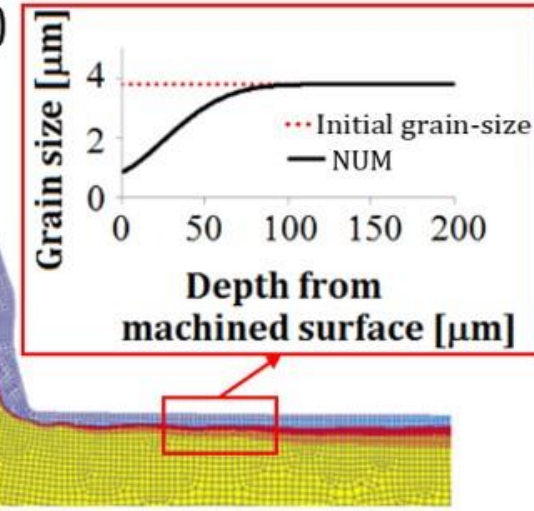

(c)
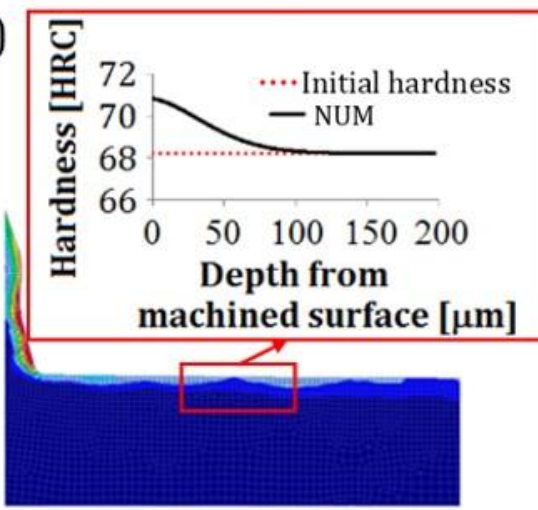

Grain $[\mu \mathrm{m}]$

3.79

3.11

2.43

1.76

1.08

0.00

Hardness

(HRC)

75.0

74.1

73.3

72.4

71.6

70.7

69.9

69.0

68.2 (b)

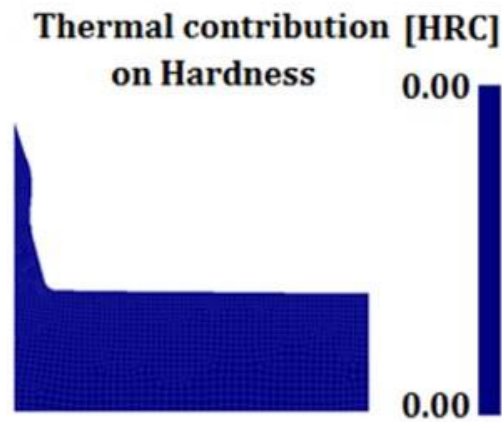

(d)

Mechanical contribution [HRC] on Hardness

6.8

5.9

5.1

4.2

3.4

2.5

1.7

0.8

0.0

Figure 12. Dry machining at $V_{c}=45 \mathrm{~m} / \mathrm{min}$ and $h=0.10 \mathrm{~mm}$, predicted results: (a) grain-size distribution, (b) thermal contribution on hardness, (c) micro-hardness distribution, and (d) mechanical contribution on hardness.

\section{Conclusions}

Plastic strain and WL thicknesses generated by dry and cryogenic machining of AISI 52100 hardened-steel are investigated experimentally. The experimental results show a WL thickness slightly greater for dry cutting when compared to the cryogenic cooling. These results also reveal a plastic strain threshold governing the WL formation when machining under cryogenic cooling conditions. This plastic strain threshold can be helpful to select desired process parameters for WLs-oriented problems at shop floor. Finally, FEM simulations confirm the experimental outcomes that microstructural changes (i.e. grain-size and hardness) in the machined surface and subsurface are only mechanically induced through SPD due to the cryogenic cooling action.

\section{Acknowledgements}

This work is supported by the National Natural Science Foundation of China (51722505 and 51721092). The authors gratefully thank Ms. Yan Zhu for her help on the FIB and SEM operations in the Micro-Nano Manufacturing Center, School of Mechanical Science and Engineering HUST.

\section{References}

[1] Guo, Y. B., Schwach, D. W., 2005, An experimental investigation of white layer on rolling contact fatigue using acoustic emission technique, International Journal of Fatigue, 27(9): 1051-1061. 
[2] Stead, J., 1912, Micro-metallography and its practical application, Journal of Western Scottish Iron and Steel Institute, 19: 169-204.

[3] Chou, Y. K., and Evans, C. J., 1998, Process effects on white layer formation in hard turning, Transactions of NAMRI/SME, 26: 117-122.

[4] Umbrello, D., and Rotella, G., 2012, Experimental analysis of mechanisms related to white layer formation during hard turning of AISI 52100 bearing steel, Materials Science and Technology, 28(2): 205-212.

[5] Ramesh, A., Melkote, S., Allard, L., Riester, L., and Watkins, T., 2005, Analysis of white layers formed in hard turning of AISI 52100 steel, Materials Science and Engineering: A, 390(1-2): 88-97.

[6] Mondelin, A., Valiorgue, F., Rech, J., Coret, M., and Feulvarch, E., 2013, Modeling of surface dynamic recrystallisation during the finish turning of the 15-5PH steel, Procedia CIRP, 8: 311-315.

[7] Mondelin, A., Rech, J., Feulvarch, E., and Coret, M., 2014, Characterisation of surface martensite-austenite transformation during finish turning of an AISI S15500 stainless steel, International Journal of Machining and Machinability of Materials, 15: 101-121.

[8] Hosseini, S., Klement, U., Yao, Y., and Ryttberg, K., 2015, Formation mechanisms of white layers induced by hard turning of AISI 52100 steel, Acta Materialia, 89: 258-267.

[9] Ramesh, A., and Melkote, S. N., 2008, Modeling of white layer formation under thermally dominant conditions in orthogonal machining of hardened AISI 52100 steel, International Journal of Machine Tools \& Manufacture, 48(3): 402-414.

[10] Guo, Y. B., Warren, A. W., and Hashimoto, F., 2010, The basic relationships between residual stress, white layer, and fatigue life of hard turned and ground surfaces in rolling contact, CIRP Journal of Manufacturing Science and Technology, 2(2): 129-134.

[11] Zhang, X.-M., Chen, L., Ding, H., 2016, Effects of process parameters on white layer formation and morphology in hard turning of AISI52100 steel. Journal of Manufacturing Science and EngineeringTransactions of the ASME, 138(1), p. 074502.

[12] Zurecki, Z., Ghosh, R., Frey, J.-H., 2003, Investigation of White Layers Formed in Conventional and Cryogenic Hard Turning of Steels, ASME International Mechanical Engineering Congress \& Exposition, 211220.

[13] Umbrello, D., Hua, J., and Shivpuri, R., 2004, Hardness-based flow stress and fracture models for numerical simulation of hard machining AISI 52100 bearing steel, Materials Science and Engineering: A, 374 (1-2): 90100.

[14] Umbrello, D., Caruso, S., and Imbrogno, S., 2016, Finite element modelling of microstructural changes in dry and cryogenic machining AISI 52100 steel, Materials Science and Technology, 32 (11): 1062-1070.

[15] Umbrello, D., 2013, Analysis of the white layers formed during machining of hardened AISI 52100 steel under dry and cryogenic cooling conditions, International Journal of Advanced Manufacturing Technology, 64(5-8): 633-642.

[16] Nie, G.-C., Zhang, X.-M., Zhang, D., and Ding, H., 2018, An experimental study of the white layer formation during cryogenic assisted hard machining of AISI 52100 steel, Procedia CIRP, 77: 223-226.

[17] Jawahir, I S., Attia, H., Biermann, D., et al., 2016, Cryogenic manufacturing processes. CIRP Annals Manufacturing Technology, 65(2): 713-736.

[18] Outeiro, J., Campocasso, S., Denguir, L., Fromentin, G., Vignal, V., and Poulachon, G., 2015, Experimental and numerical assessment of subsurface plastic deformation induced by OFHC copper machining, CIRP Annals - Manufacturing Technology, 64(1): 53-56.

[19] Zhang, D., Zhang, X.-M., Leopold, J., and Ding, H., 2017, Subsurface deformation generated by orthogonal cutting: analytical modeling and experimental verification, Journal of Manufacturing Science and EngineeringTransactions of the ASME, 139(1), p. 094502. 